Biol. Neonate 1970;16:I-IV

\title{
Contents, Vol. 16, No. 1-3, 1970
}

\section{Contents}

List of Participants

1

Swyer, P. R. (Toronto): Methods of Artificial Ventilation in the Newborn (IPPV) 3

Martin-Bouyer, G. (Paris): Positive-Pressure Respirators, and Description of the

French Machine RPR 16

Stern, L. (Montreal): Description and Utilization of the Negative Pressure

Apparatus 24

Discussion (Chairman: Dr. Strang) 30

Geubelle, F. and Senterre, J. (Liège): Methods of Investigation of the Mech

anics of Breathing in the Artificially Ventilated Newborn

Senterre, J. and Geubelle, F. (Liège): Measurement of Endoesophageal Pressure

in the Newborns 47

Stahlman, M. (Nashville, Tenn.): Circulatory Studies in Clinical Hyaline Mem

brane Disease 54

Discussion (Chairman: Dr. Swyer) 57

Cooke, R. (Observatory, Cape, South Africa): Practical Problems Associated

with Artificial Ventilation in the Newborn Infant

Couchard, M. and Amiel, C. (Paris): The Arterial Sampling for Assessment of

$\mathrm{PaO} 2, \mathrm{PaCo}$, Acid-Base Balance, etc 74

Dehan, M. (Paris): Problems of Weaning of Mechanical Ventilation in Premature

Babies with Hyaline Membrane Disease

81

Discussion (Chairman: Dr. Stahlman)

Gruber, H. S. and Klaus, M. H. (Cleveland, O.): Another to Assisted Ventilation

in the Treatment of Hyaline Membrane Disease (HMD) 87

Swyer, P. R. (Toronto): Patient Monitoring during Artificial Ventilation 88

Stern, L. (Montreal): Temperature Control, Hydration and Feeding, Bilirubin and Calcium Metabolism 92

Larroche, J. Cl. (Paris): Umbilical Catheterization: its Complications. Anatomical Study 101

Stahlman, M. (Nashville, Tenn.): The Relation of Disseminated Intravascular Coagulation to Hyaline Membrane Disease 117

Discussion (Chairman: Dr. Räihä) 119

Relier, J.P. (Paris): Mechanical Complications of Artificial Ventilation in the Newborn 122

Stahlman, M. (Nashville, Tenn.): Long Time Results of Respirator Therapy . . 133

Discussion (Chairman: Dr. Stern) 138

Strang, L.B. (London): Clinical Indications for Mechanical Ventilation in New

born Infants 142

IV 


\section{Contents}

Swyer, P.R. (Toronto): Results of Artificial Ventilation. Experience at the Hospital for Sick Children, Toronto 148

Stern, L. (Montreal): Results of Artificial Ventilation in the Newborn

Martin-Bouyer, G.; Monset-Couchard, M.; Bomsel, F.; Larroche, J.Cl.; Amiel-Tison, Cl. and Minkowski, A. (Paris): Artificial Ventilation in

Hyaline Membrane Disease. Analysis of a Series (130 Cases) 164

Räihä, N. and Vapaavuori (Helsinki): Artificial Ventilation of the Very Small

Premature Infant with Respiratory Insufficiency 184

Discussion (Chairman: Dr. Geubelle) 187

Swyer, P. R. (Toronto): Summary of Conference Proceedings 